\title{
Different Positions of the Impella Device Between the Axillary and Femoral Approaches
}

Yuji Nishimoto, MD; Keita Okayama, MD; Masanao Toma, MD; Yukihito Sato, MD

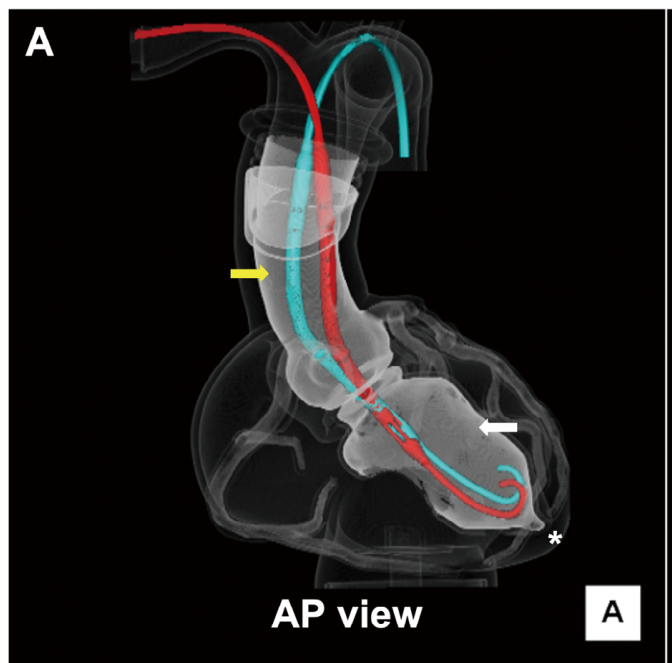

B

C

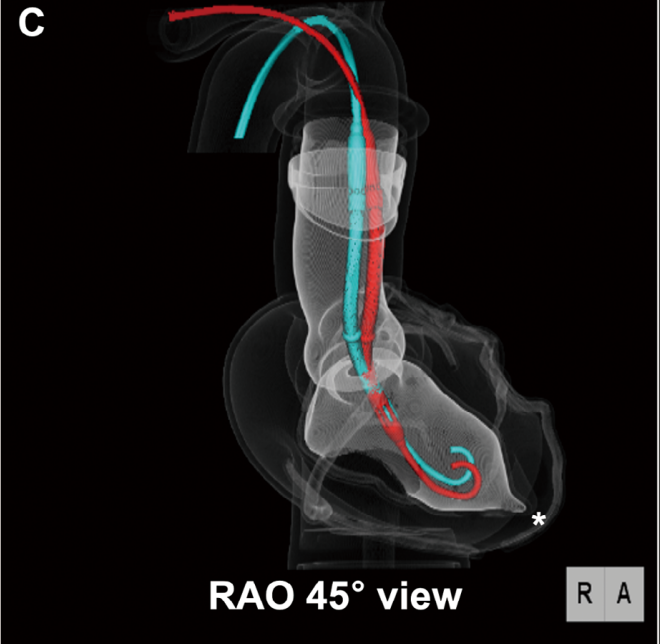

D

Figure. (A) Anterior-posterior (AP), (B) left anterior oblique $(\mathrm{LAO}) 45^{\circ},(\mathbf{C})$ right anterior oblique (LAO) $45^{\circ}$, and (D) cranial oblique (CRA) $90^{\circ}$ views. The red and light blue lines indicate the Impella CP inserted through the axillary and femoral arteries, respectively. The white and yellow arrows indicate the left ventricular and ascending aorta, respectively. The asterisks indicate the left ventricular apex.

Received January 6, 2022; accepted February 8, 2022; J-STAGE Advance Publication released online February 19, 2022 Time for primary review: 33 days

Department of Cardiology, Hyogo Prefectural Amagasaki General Medical Center, Amagasaki (Y.N., M.T., Y.S.); Department of Cardiology, Osaka University Graduate School of Medicine, Osaka (K.O.), Japan

Mailing address: Yuji Nishimoto, MD, Department of Cardiology, Hyogo Prefectural Amagasaki General Medical Center, 2-17-77 Higashinaniwa-cho, Amagasaki 660-8550, Japan. E-mail: yuji.nishimoto@gmail.com

All rights are reserved to the Japanese Circulation Society. For permissions, please e-mail: cr@j-circ.or.jp

ISSN-2434-0790 
H emolysis is less frequent following surgical implantation of the Impella 5.0 (Abiomed Japan, Tokyo, Japan) through the axillary artery (AxA) than percutaneous implantation of the Impella CP through the femoral artery (FA); ${ }^{1}$ however, little is known about the underlying mechanism.

Using the HEARTROID system (JMC, Yokohama, Japan), a training system with a 3-dimensional printed heart model, we took computed tomographic images of the Impella $\mathrm{CP}$ inserted through the AxA and FA, and superimposed those images on 3-dimensional constructions (Supplementary Movie). The anterior-posterior view revealed that the Impella from the AxA was located on the lesser curvature side (Figure A). The left anterior oblique $45^{\circ}$ view revealed that the Impella from the FA was located on the greater curvature side (Figure B). The left and right oblique $45^{\circ}$ views confirmed that the Impella from the AxA was located closer to the left ventricular (LV) apex than that from the FA (Figure B,C). The cranial oblique $90^{\circ}$ views demonstrated that the Impella from the AxA was located anteriorly and more coaxially to the LV apex (Figure D), which may suggest that the Impella from the AxA is anatomically favorable for LV suction and subsequent hemolysis.

\section{Acknowledgments}

The authors are grateful to Mr. Yukihiro Enchi and Mr. John Martin for the 3-dimensional computed tomographic imaging and grammatical assistance, respectively.

\section{Disclosures}

None of the authors have any conflicts of interest to declare.

\section{Reference}

1. Chen S, Paone D, Spellman L, Ranganath NK, Carillo JA, Gidea CG, et al. Comparison of device-specific adverse event profiles between Impella platforms. $J$ Card Surg 2020; 35: 33103316.

\section{Supplementary Files}

Supplementary Movie. The superimposed 3-dimensional rotational computed tomographic images of the HEARTROID with the impella CP inserted through the axillary and femoral arteries.

Please find supplementary file(s);

http://dx.doi.org/10.1253/circrep.CR-21-0164 